\title{
Article
}

\section{What to look for during constant observations: Expert consensus and a tool for observations recording}

Chu, Simon, Lambert, Katie and Baker, Alison

Available at http://clok.uclan.ac.uk/29386/

Chu, Simon ORCID: 0000-0001-8921-4942, Lambert, Katie and Baker, Alison (2020) What to look for during constant observations: Expert consensus and a tool for observations recording. Journal of Psychiatric and Mental Health Nursing, 27 (1). pp. 77-86.

It is advisable to refer to the publisher's version if you intend to cite from the work. http://dx.doi.org/10.1111/jpm.12555

For more information about UCLan's research in this area go to http://www.uclan.ac.uk/researchgroups/ and search for < name of research Group>.

For information about Research generally at UCLan please go to http://www.uclan.ac.uk/research/

All outputs in CLoK are protected by Intellectual Property Rights law, including Copyright law. Copyright, IPR and Moral Rights for the works on this site are retained by the individual authors and/or other copyright owners. Terms and conditions for use of this material are defined in the policies page.

\section{CLoK}

Central Lancashire online Knowledge www.clok.uclan.ac.uk

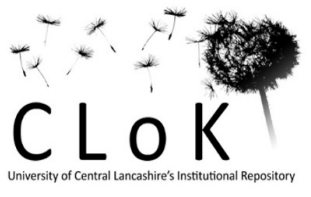




\title{
What to look for during constant observations: Expert consensus and a tool for observations recording
}

\author{
Simon Chu ${ }^{1,2}$, Katie Lambert ${ }^{1,2}$, Alison Baker ${ }^{1}$
}

${ }^{1}$ Ashworth Research Centre, Ashworth Hospital, Mersey Care NHS Foundation Trust, UK ${ }^{2}$ School of Psychology, University of Central Lancashire, UK

Corresponding author contact:

simon.chu@merseycare.nhs.uk

\section{Running title:}

Developing expert consensus about observations

\section{Acknowledgements}

This study would not have been possible without the support provided by the members of the Delphi panel who generously gave their time and offered their expertise.

\section{Ethics}

The study was granted ethical approval by the University of Central Lancashire Research Ethics Committee.

\section{Note}

Katie Lambert is currently at Coastal Child and Adult Therapeutic Services, Poulton-le-Fylde, Lancashire, UK. 


\begin{abstract}
Introduction. Supportive observations are common in mental health care but there are no guidelines on best practice or what should be documented in observations records. Aim. To develop expert consensus on the important aspects of patient presentation that inform clinical decision-making about observations, and to develop a recording tool from this consensus. Method. A Delphi methodology was used to consult an expert panel of mental health clinicians and academics to agree on what aspects of patient presentation during constant observations are important in informing clinical decisions. Thematic analysis was applied to the agreed item set to extract common aspects of presentation and behaviour. Results. The panel considered 118 individual items across three rounds of consultation and agreed that 51 items were important to clinical decisions about observations. Thematic analysis found six man themes: agitation, self-harm and suicide, violence, negative influence, disengagement and positive behaviour. Sub-themes were used to create the MerseyCare Supportive Observations Recording Tool (MSORT). Discussion. These data represent the first expert consensus on the aspects of patient presentation that are important to clinical decisions. Implications for practice. Consensus items should be recorded in observations records and be considered in decision-making about observations. The MSORT may aid observations recording.
\end{abstract}

\title{
Relevance Statement
}

The research presented here 1 . develops expert consensus on the aspects of patient presentation that are clinically meaningful during observations and 2 . develops a tool to assist staff in recording meaningful observations information. Key implications for mental health nursing are that staff discussions about clinical decisions on observations should involve the aspects of patient presentation that are raised in the expert consensus, and furthermore, that the use of the recording tool developed here should aid in that process because it facilitates the recording of the key aspects of patient presentation.

\section{Accessible Summary}

What is known on the subject

- Supportive observations is the practice of closely monitoring patients who are acutely unwell in order to keep them safe

- There are no formal guidelines for nursing staff on what to observe during observations

What the paper adds to existing knowledge

- A consensus of expert opinion suggests that the clinically meaningful behaviours in supportive observations focus on six factors: agitation, self-harm and suicide, violence, negative influence, disengagement and positive behaviour. 
What are the implications for practice

- These aspects of patient presentation should be a part of the decision-making discussions about observations. The Mersey Care Supportive Observations Recording Tool that emerged from this consensus may assist with recording the relevant information.

\section{Introduction}

Supportive observation is the practice of maintaining an increased level of observation over patients when they are acutely ill and may be at an elevated risk of harming themselves, harming others or absconding (Manna, 2010; Wood et al., 2018). Supportive observations may be conducted at different levels of intensity, with the highest levels involving one-toone nursing care with dedicated staff keeping the patient within eyesight, and even within arms length, at all times. These higher levels of observations are referred to as constant observations, specialling, and one-to-one nursing amongst other terminologies (Bowers, Gournay \& Duffy 2000).

The use of constant observations is not uncommon. One review found that up to $20 \%$ of people admitted to inpatient mental health services are placed under some form of intensive observation (Bowers \& Park, 2001). An audit of the prevalence of constant observations in three UK secure mental health units in 2013-14 (Lambert et al. 2018) found that $30 \%$ of all inpatients were placed on constant observations at some point during the year, and that patients spent 85 hours per 100 occupied bed days in constant observations overall. Whilst commonly prescribed to keep patients safe, the use of constant observations is contentious because it can be an intrusive form of care that denies the patient privacy and erodes dignity (Barnicot et al., 2017; Holyoake, 2013; Mason, Mason-Whitehead \& Thomas 2009). However, patients also see the value in constant observations in providing safety (Barnicot et al., 2017) and particularly if there is a strong element of therapeutic interaction between staff and patient during observations (Insua-Summerhays et al, 2018). The practice can be demoralising also for staff conducting the observations (Barnicot et al. 2017). Recent recommendations suggest that constant observations should be conducted by experienced and skilled staff with expertise in engaging patients (Schroeder 2016) and thus advance the role from one of maintaining surveillance and safety, to one of active therapeutic engagement. Nevertheless, there is a wide variation in the type of staff who undertake observations duties on mental health wards and it is a task frequently assigned to less qualified and less experienced staff (Ray, Perkins \& Meijer 2011).

The National Institute for Health and Care Excellence (NICE) guideline on the management of violence in healthcare settings recommends that staff should "use the least intrusive level of observation necessary, balancing the service user's safety, dignity and privacy with the need to maintain the safety of those around them" (p.215, National Institute for Health and 
Care Excellence 2015). Nevertheless, there are no national guidelines on what factors determine the warranted level of intrusion and no guidance or best practice standards for conducting observations. Rather, organisations are left to determine their own local observations policies and guidelines on decision-making (Bowers, Gournay \& Duffy 2000). However, both staff and patients have linked good decision-making about observations to good communication with the patient, good communication between staff, and taking positive risks using the available information (Barnicot et al. 2017). An analysis of completed suicides by inpatients under observation in UK mental health units between 2006 and 2012 (Flynn et al. 2017) suggested that many cases involved inexperienced staff, staff who were unfamiliar with the patient, and a lack of information on the patient's presentation during the observations period. The implication is that good decision-making about observations that balance safety and dignity, stem from having experienced communicative staff equipped with current information about the patient.

This raises the question of what information about the patient is meaningful to clinical decisions about constant observations. Similar issues about more general patient presentations were raised by Bowers et al. (2011) who were motivated to develop the Nursing Observed IIIness Intensity Scale (NOIIS), a recoding tool designed be completed by staff on each shift to capture a summary of a patient's presentation during that period. Similarly, Björkdahl et al. (2011) used an expert consensus-building methodology to achieve agreement on the important aspects of the presentation of suicidal patients. This led to the development of the Suicidal Patient Observation Chart (SPOC) to record constant observations that were specifically relevant to patients at risk of suicide. Their view was that, during constant observations, critical information may go unrecorded or the observer may fail to communicate information to the multidisciplinary team, potentially placing patient safety at risk. Using a structured recording tool during constant observations allowed for important aspects of presentation to be recorded so that this could be tracked over time and provide meaningful information to clinical teams. However, no evidenced structured tool exists for recording more general constant observations and our ultimate aim was to develop such a tool.

One issue that will inform clinical decision-making on observations is a consensus on the facets of patient presentation that inform these decisions. The literature on supportive observations presents no guidelines on what aspects of behaviour staff should observe and the aim of the present study is to gather a consensus opinion from a panel of experts about this issue.

\section{Part 1}

\section{Method}




\section{Overview}

The study used a Delphi methodology to ascertain the consensus view from a panel of experts regarding important aspects of a patient's presentation during constant observations. The Delphi methodology captures expert opinion through a form of group consultation with the ultimate aim of achieving a consensus regarding a topic of uncertainty and/or limited clarity (Dalkey \& Helmer, 1963; Iqbal \& Pipon-Young, 2009). A panel of experts responds to questionnaires in two or more rounds and, after each round, the answers are aggregated anonymously and returned to panellists for review and agreement (Murphy et al., 1998). After a number of iterations, a consensus is reached.

Ethics

The questionnaire study was granted ethical approval by the University of Central Lancashire Research Ethics Committee, and was also approved by Mersey Care NHS Foundation Trust. Written informed consent was gathered from all participants prior to the start of data collection and all data was processed confidentially within the research team in line with university research data processing guidelines.

Participants

Participants were recruited to join the expert panel through purposive sampling. Panellists were either academic experts, having published in the area of supportive observations and/or mental health nursing, or senior mental health nursing staff (ward managers, senior clinical nurses, nurse managers, modern matrons). Contact details for relevant academic staff were found through their relevant journal publications. Contact details for clinical staff were found by contacting forensic mental health units throughout the UK and requesting contact details of ward managers and senior clinical staff who may be interested in participation. All potential panellists were sent a study information sheet by email and asked to formally agree to participation by return email. There are no agreed standards or guidelines in respect of sample size requirements for Delphi studies (Murphy et al., 1998) however Turoff (2002) recommended the size of an expert panel to be between 10 and 50 panellists. In the present study, 53 participants ( 8 academic staff and 45 clinical staff) agreed to join the expert panel.

Development of initial item set

An initial set of items used to form the first round of Delphi consultation was developed from two sources: a search of the published literature on nursing risk assessment, and interviews with nursing staff. Here, the aim was to gather an initial list of aspects of patient presentation that may be meaningful to record during special observations and may inform 
clinical decisions. The published research literature on nursing and risk assessment was searched to identify any potential areas of risk that professionals may potentially consider when monitoring observations. In line with structured professional judgement and current risk assessment practice, which is based upon recovery-based approaches and positive psychology literature (Seligman \& Csikszentmihalyi, 2000; Hammond, 2010; Boardman \& Roberts, 2014), we also included items that reflected individual strengths and engagement in positive behaviour. Semi-structured interviews were also held with experienced nursing staff $(n=11)$ working in forensic mental health who were regularly involved in implementing constant observations. Staff were asked to consider behaviours that were observable during constant observations that may indicate risk or deterioration in mental state, as well as behaviours that may indicate stabilising or improvement in mental state. Any behaviour that was raised as potentially informative, either by staff or in the somewhat limited literature, was added to the initial item set. This resulted in 85 items being compiled from the literature and interviews.

Round 1

Panellists were contacted by email and asked to consider the initial 85-item set of behaviours that were potentially meaningful in constant observations (i.e. where the patient is kept within eyesight or arms length at all times). Panellists were asked to indicate which of the items they considered to be 'important for staff to monitor' during these periods. Panellists responded yes or no to each item and were also asked to suggest further items that they considered to be clinically important. Panellists were given four weeks to respond to Round 1 and panellists who had not responded after three weeks were sent a reminder of the four week deadline. $63 \%$ of panellists $(n=34)$ responded to Round 1 . These responses were collated and items that received a positive response from $50 \%$ or more of the responders were retained for Round 2. 69 items were retained for Round 2 and 16 items were removed. 33 new items were suggested by the panel for inclusion in Round 2 . It is worth noting here that the consensus rate was set at $50 \%$ in order to gather as broad a range of factors as possible. There was an expectation that the items would later be subjected to an analysis to extract common themes and so the focus at this point in the study was in terms of balancing inclusivity of items and broad agreement by the panel.

Round 2

Panellists who responded to Round 1 were sent the 101 items that emerged from Round 1, along with (for old items) information on the proportion of the panel that had chosen each item. Panellists were asked again to consider if each item should be included and, if so, to consider how influential they felt each item would be in informing the clinical decision to continue, increase or decrease the level of constant observations. Ratings were on a 3-point scale (very influential, influential, somewhat influential). Again, the panel was given four 
weeks to respond and reminded after three weeks. $79 \%$ of panellists ( $n=27$ ) responded to Round 2. Responses were collated and items that were rated as 'influential' or 'very influential' by at least $50 \%$ of panellists were retained. 54 items were retained and 47 items were removed.

\section{Round 3}

Panellists who responded to Round 2 were sent the 54 items that emerged from Round 2 along with information on the proportion of the panel that had rated each item as very influential or influential. Panellists were then asked to again consider, in light of the feedback from the panel in Round 2, how influential they felt each item would be in clinical decision-making and to rate the level of influence using the same scale as in Round 2. Again, the panel was given four weeks to respond and reminded after three weeks. $81 \%$ of panellists $(n=22)$ responded to Round 3 . Responses were collated and items that were rated as 'influential' or 'very influential' by more than $50 \%$ of panellists were retained. 51 items were confirmed to be at least 'influential' by the panel and 3 items were removed. This information was fed back to the panel members who were thanked for their help.

- Table 1 around here please -

\section{Results and Discussion}

Forty-two percent $(22 / 53)$ of the initial expert panel responded to all three rounds of the Delphi consultation. A total of 118 separate items ( 85 in the initial set, 33 additional items suggested by panel members) were considered by the panel during the process and the consultation resulted in a consensus comprising 51 items that were considered influential to clinical decisions about observations. All items that were used in the three rounds of Delphi consultation are presented in Table 1 with the proportion of the panel that selected each item in each round. Some items that initially achieved high agreement in Round 1 were rated less influential to clinical decision-making in successive rounds, reflecting the fact that while some factors may be important aspects of a patient's presentation (e.g. 'showed verbal aggression', 'expressed sadness'), they may not necessarily influence clinical decisions concerning observations. Many other items were clearly influential in all three rounds of consultation (e.g. 'expressing hopelessness', 'communicate intention to harm others') having been rated as both important and influential. 'Expressing hopelessness' was the item that achieved the highest level of agreement as a factor that would influence clinical decisions, followed closely by items concerning attempts to self-harm and the expression of suicidal ideation. In terms of positive aspects of presentation, the behaviour that achieved the highest level of agreement from the panel concerned the patient's ability to demonstrate insight into why they were under observation. 
During the Delphi process, the research team became aware that a small number of items in the consultation set were bound in language that may be interpreted as discriminatory and intolerant, e.g. 'pushing boundaries', 'complaining about rules', 'noncompliant'. This issue was subsequently raised by a reviewer who noted that those items perpetuated a 'them and us', paternalistic framework. Ultimately, those items did not meet the criterion for agreement and were removed from the consultation in Round 1 or 2, but had any discriminatory or biased items met the criterion for inclusion, they would have been reworded to reflect the more strength-based approach that characterises a modern health service.

The final set of 51 items represents the first consensus of expert opinion about the aspects of patient presentation that inform clinical decision-making on supportive observations. This consensus is important because it provides evidence for an agreed reference list of the types of behaviour of which staff should be mindful when conducting constant observations with patients. Ideally, the incidence of these behaviours should be noted in observations records and changes in presentation over time should be discussed in team meetings when making decisions about observations. An informative record of aspects of presentation that inform clinical decisions is valuable. Mental health care is frequently characterised by institutional risk aversion where staff may often err on the side of safety (Manuel \& Crowe 2014) but data reported by Barnicot et al. (2017) suggested that one factor associated with good decision-making about observations is the confidence to take positive risks. Informative records of observations detailing evidence that suggests a patient's improving presentation may support such positive risk-taking.

The Delphi method is a well used methodology suited to developing consensus and agreement where none has previously been formalised. It has frequently been implemented in mental-health research when a group agreement is required, and particularly in determining collective values and beliefs (for review, see Jorm 2015). For the present purposes, it was well suited to quickly gathering views from a range of academics and clinicians who were geographically diverse, and because the questions posed to them were focused and limited, the interpretation of their responses was simple. In contrast, other qualitative methodologies (e.g. interview/focus groups) that provide what may seem to be richer data also requires intensive nuanced analysis. The Delphi methodology offered the opportunity to gather a broad range of views and achieve consensus relatively quickly.

We developed a consensus view on the aspects of patient presentation that inform clinical decisions on observations. It may be beneficial to observations records for a tool to assist staff in recording these informative aspects of presentation and we set out to construct such a tool from the consensus developed in Study 1 . We also noted a degree of similarity between many items in the consensus set and items frequently addressed similar types of behaviour, related behaviours or different ways of expressing similar behavioural concepts 
(e.g. 'displayed increased agitation', 'showed unpredictable behaviour', 'high changeability in mood', 'displayed heightened emotional state'). In order to develop a recording tool, Part 2 implemented a basic thematic analysis on the item set to distil the items down to broader concepts that would lend themselves more easily to a user-friendly tool.

\section{Part 2}

The aim of Part 2 was to apply thematic analysis on the raw consensus items that resulted from Part 1 of this research in order to develop a simple tool to assist staff to record the informative aspects of patient presentation during constant observations.

\section{Method}

In order to examine possible commonalities and themes that may be present in the consensus set of behaviours that emerged from the expert panel, the 51 items were explored using thematic analysis. Thematic analysis is a qualitative analysis methodology for identifying, analysing and reporting patterns or themes within narrative data (Braun \& Clarke, 2006). A constructivist method of thematic analysis was applied that is inductive in perspective, thus the themes should be strongly related to the data (Braun \& Clarke, 2006). The data was coded, themes explored and reviewed and then labelled resulting in six themes. This approach allowed for the nature of the theme to be accurately reflected and ensured the data within the themes fitted together meaningfully while also having clear and identifiable distinctions between themes (Patton, 1990; Braun \& Clarke, 2006). The thematic analysis was conducted independently by two raters and subsequently compared for similarity and contra-occurrence. This process sought to increase the trustworthiness in terms of the credibility of the emerging themes (Braun and Clarke, 2006; Shenton, 2004).

- Table 2 around here please -

\section{Results and Discussion}

Six main themes, 13 major sub-themes, and 26 minor sub-themes were drawn from the 51 original consensus items. The sets of themes and the items from which they were derived are given in Table 2. The main themes were:

i. Agitation and unstable behaviour, such as instability in emotions, thoughts and behaviour, as well as sexually inappropriate behaviour. These broadly addressed thoughts and behaviour that was unpredictable, or out of character.

ii. Self-harm and suicide, including suicidal ideation and expressing thoughts of self-harm as well as actual self-harm behaviour; exhibiting behaviour that facilitates self-harm, such as trying to obtain objects with which to self-harm.

iii. Violence or threatening behaviour, including actual violence towards people or property, threatening such behaviour or expressing thoughts of such behaviour. 
iv. Negative influence, including subversion and behaviours that impact negatively upon others, such as bullying and grooming behaviours.

v. Disengagement, relating to withdrawal from others or from activities, and communicating low self-esteem or despondence.

vi. Positive behaviour, relating to engaging positively with staff and peers, both socially and therapeutically, as well as accepting treatment and support, and showing stability in presentation.

Some of the extracted themes echoed those present in other patient observation scales (e.g. NOIIS, Bowers et al., 2011, and SPOC, Björkdahl et al., 2011) and risk management literature (e.g. Morgan, 2000) in terms of factors such as agitation, violence and self-harm, providing converging evidence that clinically these issues are core aspects of patient presentation. Furthermore, the findings expanded the spectrum of important factors into broader issues concerning risk, such as disengagement from staff and the therapeutic milieu, and actively exerting a negative influence on others. In line with the theoretical underpinnings of positive psychology (Seligman \& Csikszentmihalyi, 2000; Hammond, 2010; Boardman \& Roberts, 2014), indicators of a more positive and stabilising presentation also emerged as important aspects of presentation, underlining the value of a holistic balanced account of the patient (Rogers, 2000) in the clinical decision-making process.

The sets of themes were then used to construct separate checklist tools with differing levels of detail to assist staff to record the occurrence of relevant and meaningful behaviour during constant observations. The tool was named the MerseyCare Supportive Observations Recording Tool (MSORT). Additional items concerning sleep were added to each set. Sleep was not identified in the Delphi consultation as being clinically informative in constant observations but feedback from staff indicated a need to record the periods when the patient was asleep (and thus not expressing any of the other behaviours in the set). Space was also added to each tool to allow staff the option of adding individual relapse indicators to the tool. Accordingly, one sleep item and three individual indicator items were added to the 13 major sub-themes to form a brief 17-item recording tool (called the MSORT17), and two sleep items and three individual indicator items were added to the 26 minor subthemes to form a more detailed 31-item recording tool (called the MSORT31). At the end of every period of constant observation (e.g. hourly, two-hourly) items on the tool may be checked if they occurred during that period, and the tool thus serves as a record of the patient's presentation over a period of time.

Note: The MSORT is freely available for download from https://tinyurl.com/get-msort

\section{General discussion}


The aim of this research was to develop agreement on the aspects of a patient's presentation that would inform clinical decision-making during constant observations, by consulting with an expert panel of senior mental health nurses and academics. A second aim was to use the agreed consensus items to develop a simple tool to assist nursing staff to record these aspects of patient presentation during periods of constant observations.

Across three rounds of consultation, the Delphi process asked members of the expert panel to consider the relevance and importance of 118 separate items to clinical decision-making in constant observations. Ultimately, the panel agreed that 51 items were important. Through thematic analysis, the set of items was distilled into smaller groups of increasingly more general behavioural factors with broader themes that reduced the item set while maintaining the essential topics of concern that were highlighted in the original items. This resulted in two versions of the recording tool with different levels of detail to suit local needs.

The use of checkbox observations tools, and indeed the practice of constant observations in general, may inspire criticisms of the objectification of patients and the view of observations as a chore to be done, contributing to impersonal care (Cox et al 2010). We agree that patients under constant observations require compassionate care from trained professional nursing staff who view the patient as an individual with complex needs, and use of the MSORT tool must not diminish any efforts to therapeutically engage patients during observations. Rather, the use of the recording tool could potentially encourage better practice in a number of ways. The tool could act as a reminder to staff about the facets of presentation that are clinically meaningful, and thus bring an awareness of these aspects of behaviour more into the forefront during observations. Better awareness may also encourage staff to engage more with the patient during observations, which is a practice that numerous studies have linked to patient wellbeing and good decision-making (e.g. Barnicot et al, 2017; Jones et al, 2000). This may be particularly beneficial when constant observations are being conducted by less experienced staff who may not be familiar either with the patient or the issues to be aware of during constant observations (Ray et al. 2011). The completed tool, as a record both of observations and change in presentation over time, could also be beneficial as a document for discussion with the patient to help involve them in decision-making. Shared decision-making and good communication with the patient have been shown to be beneficial to outcomes (Barnicot et al. 2017, Joosten et al. 2008).

The consensus that has resulted from this research - consensus around the aspects of patient presentation that inform clinical decisions on observations - will correspond with many of the kinds of patient behaviours that are already discussed in clinical team meetings. These team discussions are informed by the same kind of clinical judgements that are held by the members of the expert panel who contributed their views to the Delphi consultation from which the consensus is drawn. In that respect, the consensus tells us nothing 'new'; 
rather, it simply formalises and crystallises the collective wisdom of a large group of experts and presents a collective agreed opinion. This is the principal limitation of this research - it can only tell us what most participants already knew - but the aim of the project was not to discover new things but to determine what things were less important (i.e. to remove issues that the panel did not agree were important) so that clinicians could focus their discussions on what the panel agreed was more vital. The MSORT simplifies the recording of those aspects of the patient's presentation during constant observations and further research should assess the impact of the tool on decision-making, positive risk-taking and the confidence that clinical teams have in finding the balance between patient safety and dignity.

The research was conceived from a NHS Commissioning for Quality and Innovation target to improve observations in UK high secure forensic mental health services. The combined experience of the researchers included mental health nursing, forensic psychology and research methodology, and the cross-disciplinary nature of the research team is a strength of this project.

Together, this work presents an expert consensus of the aspects of a patient's presentation that meaningfully inform clinical decision-making on observations, and present a tool to assist staff in recording the relevant information during constant observations. 


\section{References}

Barnicot K., Insua-Summerhayes, B., Plummer, E., Hart, A., Barker, C. \& Priebe, S. (2017). Staff and patient experiences of decision-making about continuous observation in psychiatric hospitals. Soc Psychiatry Psychiatr Epidemiol 52:473-483.

Björkdahl, A., Nyberg, U., Runeson, B. \& Omerov, P. (2011). The development of the Suicidal Patient Observation Chart (SPOC): Delphi study. Journal of Psychiatric and Mental Health Nursing, 18, 558-561. doi:10.1111/j.1365-2850.2011.01758.x

Boardman, J. \& Roberts, G. (2014). Briefing: Risk, Safety and Recovery. Implementing Recovery through Organisational Change (ImROC). London: Centre for Mental Health and Mental Health Network. https://imroc.org/resources/9-risk-safety-recovery/ (accessed 5 January 2019)

Bowers, L., Brennan, G., Ransom, S., Winship, G. \& Theodoridou, C. (2011). The nursing observed illness intensity scale (NOIIS). Journal of Psychiatric and Mental Health Nursing, 18, 28-34. doi: 10.1111/j.1365-2850.2010.01615.x

Bowers, L., Gournay, K. \& Duffy, D. (2000). Suicide and self-harm in inpatient psychiatric units: a national survey of observation policies. Journal of Advanced Nursing, 32(2), 437-444.

Bowers L, Park A. Special observation in the care of psychiatric inpatients: A literature review. Issues Ment Health Nurs 2001; 22: 769-786.

Braun, V. \& Clarke, V. (2006). Using thematic analysis in psychology. Qualitative Research in Psychology, 3, 77-101. doi: 10.1191/1478088706qp063oa

Cox A., Hayter M. \& Ruane J. (2010) Alternative approaches to 'enhanced observations' in acute inpatient mental health care: a review of the literature. Journal of Psychiatric and Mental Health Nursing 17, 162-171. doi: 10.1111/j.1365-2850.2009.01507.x

Dalkey N. \& Helmer O. (1963). An Experimental Application of the DELPHI Method to the Use of Experts. Management Science, 9(3), 351-515. doi: 10.1287/mnsc.9.3.458

Flynn, S., Nyathi, T., Tham, S., Williams, A., Windfuhr, K., Kapur, N., Appleby, L. \& Shaw, J. (2017). Suicide by mental health in-patients under observation. Psychological Medicine, 47(13), 2238-2245. doi:10.1017/S0033291717000630

Hammond, W. (2010). Principles of Strengths based Practice. London: Resiliency initiatives.

Holyoake, DD. (2013). I spy with my little eye something beginning with O: looking at what the myth of 'doing the observations' means in mental health nursing culture. Journal of Psychiatric and Mental Health Nursing, 20(9), 840-850. doi: 10.1111/jpm.12056

Insua-Summerhays, B., Hart, A., Plummer, E., Priebe, S. \& Barnicot, K. (2018). Staff and patient perspectives on therapeutic engagement during one-to-one observation. Journal of Psychiatr Ment Health Nurs. 25:546-557

Iqbal, S. \& Pipon-Young, L. (2009). The Delphi Method. The Psychologist, 22, $598-600$.

Jones, J., Ward, M., Wellman, N., Hall, J., \& Lowe, T. (2000). Psychiatric inpatients' experiences of nursing observation - a UK perspective. Journal of Psychosocial Nursing and Mental Health Services, 38(12), 10-20.

Jorm, A. F. (2015). Using the Delphi expert consensus method in mental health research. Australian \& New Zealand Journal of Psychiatry, 49(10), 887-897. https://doi.org/10.1177/0004867415600891

Joosten EAG., De Fuentes-Merillas L., de Weert GH., Sensky T., van der Staak CPF., de Jong CAJ. (2008) Systematic Review of the Effects of Shared Decision-Making on Patient 
Satisfaction, Treatment Adherence and Health Status. Psychother Psychosom, 77, 219-226.

Lambert, K., Chu, S., Duffy, C., Hartley, V., Baker, A., \& Ireland, J.L. (2018). The prevalence of constant supportive observations in a high, medium and low secure service. BJPsych Bulletin, 42, 54-58.

Manna, M. (2010). Effectiveness of formal observation in inpatient psychiatry in preventing adverse outcomes: the state of the science. Journal of Psychiatric and Mental Health Nursing, 17, 268-273. doi: 10.1111/j.1365-2850.2009.01512.x

Manuel, J. \& Crowe, M. (2014). Clinical responsibility, accountability, and risk aversion in mental health nursing: A descriptive, qualitative study. International Journal of Mental Health Nursing, 23(4), 336-343. doi: 10.1111/inm.12063

Mason, T., Mason-Whitehead, E., \& Thomas, M. (2009). Special observations in forensic psychiatric practice: Gender issues of the watchers and the watched. Journal of Psychiatric \& Mental Health Nursing, 16, 910-918.

Morgan, S. (2000). Clinical Risk Management. A clinical tool and practitioner manual. London: The Sainsbury Centre for Mental Health.

Murphy, M. K., Sanderson, C., Black, N., Askham, J., Lamping, D., Marteau, T. \& McKee, C. (1998). Consensus development methods, and their use in clinical guideline development. Health Technology Assessment, 2, 1-88.

National Institute for Health and Care Excellence (2015). Violence and Aggression. Shortterm management in mental health, health and community settings. Updated edition. NICE Guideline NG10. London: NICE.

Patton, M. Q. (1990). Qualitative Evaluation and Research Methods ( ${ }^{\text {nd }}$ Ed). Newbury Park, CA: Sage.

Ray, R., Perkins, E., \& Meijer, B. (2011). The evolution of practise changes in the use of special observations. Archives of Psychiatric Nursing, 25(2), 90-100.

Schroeder, R. (2016). Bearing Witness: The lived experience of sitting with patients. Archives of Psychiatric Nursing, 30 (6), 678-684. doi: 10.1016/j.apnu.2016.03.005

Seligman, M. \& Csikszentmihalyi, M. (2000). Positive Psychology: An Introduction. American Psychologist, 55, 5 -14. https://doi.org/10.1037/0003-066X.55.1.5

Shenton, A. K. (2004). Strategies for ensuring trustworthiness in qualitative research projects. Education for Information, 22, 63-75. https://doi.org/10.3233/EFI-200422201

Turoff, M. (2002). The Policy Delphi. In H. Linstone \& M. Turoff (Eds.) The Delphi Method. Newark, NJ: New Jersey Institute of Technology.

Wood, V.J., Vindrola-Padros, C., Swart, N., McIntosh, M., Crowe, S., Morris, S. \& Fulop, N.J. (2018). One to one specialling and sitters in acute care hospitals: A scoping review. International Journal of Nursing Studies, 84, 61-77. 
Table 1: All prospective items surveyed in each round of Delphi consultation and the proportion of the panel meeting the criterion for each round.

\begin{tabular}{|c|c|c|c|}
\hline item & round 1 & round 2 & round 3 \\
\hline Accepting of support & 65 & 56 & 59 \\
\hline Appear under the influence of substances* & & 67 & 86 \\
\hline Appearing distant & 53 & 33 & \\
\hline Appearing facially flat & 50 & 37 & \\
\hline Appears anxious or worried & 68 & 56 & 36 \\
\hline Appears to hide feelings & 53 & 30 & \\
\hline Appropriate smiling/laughing in conversation & 56 & 44 & \\
\hline Asking peers to attack staff* & & 52 & 68 \\
\hline Asking staff to complete task & 24 & & \\
\hline Attempting to abscond* & & 81 & 91 \\
\hline Attending to personal/environmental hygiene & 62 & 48 & \\
\hline Avoidance of people/activities* & & 52 & 59 \\
\hline Body language low/sullen & 56 & 37 & \\
\hline Bullying behaviour* & & 52 & 68 \\
\hline Calm & 62 & 63 & 59 \\
\hline Communicate intention to harm others & 88 & 81 & 82 \\
\hline Communicates sense of feeling threatened & 71 & 74 & 64 \\
\hline Communicating increased stressors & 79 & 81 & 64 \\
\hline Communicating low self-esteem & 56 & 52 & 50 \\
\hline Communication limited to needs led basis & 32 & & \\
\hline Complaining about rules & 26 & & \\
\hline Complying with medication & 71 & 63 & 59 \\
\hline Conformed to treatment pathway & 62 & 59 & 68 \\
\hline Demanding behaviour & 44 & & \\
\hline Difficult to stop a conversation & 41 & & \\
\hline Discussed situation with staff & 74 & & \\
\hline Disengagement from others/activity & 65 & 52 & 55 \\
\hline Disorientated & 62 & 44 & \\
\hline Displaying increased agitation & 68 & 70 & 82 \\
\hline Displaying relapse indicators & 79 & 85 & 77 \\
\hline Disrespectful & 32 & & \\
\hline Drinking excess volumes of liquid* & & 59 & 59 \\
\hline Easily irritated by others & 65 & 41 & \\
\hline Encouraging others not to comply with care* & & 48 & \\
\hline Engaged/held appropriate open dialog & 68 & 56 & 77 \\
\hline Engagement in activity & 68 & 56 & 59 \\
\hline Engaging appropriately with staff & 79 & 63 & 77 \\
\hline Engaging therapeutically with staff & 71 & 59 & 77 \\
\hline Evidence of exaggerated self-opinion & 29 & & \\
\hline Evidence of subversion/security risk* & & 63 & 82 \\
\hline
\end{tabular}


Exercising excessively* 37

$\begin{array}{lll}\text { Exhibits anger } & 68 & 48\end{array}$

Exhibits verbal/physical sexually inappropriate behaviour $\quad 88 \quad 85$

$\begin{array}{lll}\text { Experiencing or demonstrating paranoia } & 82 & 67\end{array}$

Experiencing/responding to unseen stimuli $\quad 65 \quad 33$

Expressed intention of plans of suicide*

Expressing hopelessness or despair

$81 \quad 95$

Expressing sorrow or sadness

$88 \quad 74$

Expressing suicidal ideation

$76 \quad 41$

$97 \quad 85$

86

Expressing thoughts of wanting to self harm

Expressing unusual or odd thought content

62

Feeling victimised

Fixed stares

$65 \quad 41$

$68 \quad 37$

Frequently requesting money*

Getting involved in other patients' care* 41

Giggling at unknown events

50 15

Giving away personal Items*

Heightened emotional state

Hiding body parts from staff (self harm)

High changeability in mood

Hitting body parts against wall

Hopeful in presentation

Increased volume of telephone calls* 48

Indicated no desire toward recovery*

Indicating what interventions helped most *

Initiation of conversation surplus to needs

Irritable when needs not met

47

Low mood

Low motivation

Making plans for the future*

Manipulation of others for gain*

More positive presentation

Noncompliant

Pacing around

Pale in complexion*

Physical changes - flushed face

Pleasant demeanour

Preoccupied

Property damage

Pushing boundaries

Querying how they could self help*

Quietness

Rationalising own behaviour without minimisation

62 
Refusing to contact relatives/attend visits*

Refusing to engage in physical observations*

Refusing to get up due to negative symptoms* 37

Refusing to get up, preferring to sleep*

Repetitive or unusual movements

50

19

Requested/engaged with health promotion*

Requesting particular staff to observe them*

Requesting review of observations*

Resistant or guarded behaviour

Restlessness

Ruminating

Settled

Showed physical violence

Showed verbal aggression

Showing grooming behaviour towards others*

Showing insight into why they are on obs

Showing unusual mannerisms

Showing/expressing frustration

Slowed movement

Speech disjointed disconnected confused

Speech is fast or slowed

Sweating profusely*

Takes longer than normal to complete task

Talked with staff about situation*

Talking or mumbling to self

Threatening/hostile behaviour

50

Trying to engage in self harm

$85 \quad 70 \quad 55$

Trying to obtain objects with which to self-harm

Unusual behaviour compared to their norm*

Note: the criterion in Round 1 was responding Yes to the question of whether the item was important to monitor during constant observations; the criterion in Round 2 and Round 3 was rating the item as either influential or very influential to clinical decisions.

*item suggested by the panel after Round 1. 
Table 2: Results of the thematic analysis extracting common themes from the original 51 items

\begin{tabular}{|c|c|c|c|}
\hline 7 items & 14 items & 27 items & 51 original items \\
\hline \multirow{5}{*}{ AGITATION } & \multirow{3}{*}{ Unstable behaviour } & Instability in emotion & $\begin{array}{l}\text { Displayed a heightened emotional state/elevated mood } \\
\text { Shown high changeability in mood }\end{array}$ \\
\hline & & Instability in behaviour & $\begin{array}{l}\text { Displayed increased agitation } \\
\text { Displaying behaviours unusual to their normal presentation } \\
\text { Showed unpredictable behaviour }\end{array}$ \\
\hline & & prn for control & Requested/used PRN for control \\
\hline & Irrational thoughts & Instability in thoughts & $\begin{array}{l}\text { Communicated a sense of feeling threatened } \\
\text { Experienced or demonstrated paranoia }\end{array}$ \\
\hline & Sexually in appropriate & Sexually inappropriate & Exhibited verbal or physical sexually inappropriate behaviour \\
\hline \multirow{5}{*}{ SELF-HARM/SUICIDE } & \multirow{2}{*}{ Thoughts of self-harm/suicide } & Thoughts of self-harm & Expressed ideas/thoughts of self harm \\
\hline & & Thoughts of suicide & Expressed suicidal ideation \\
\hline & \multirow{3}{*}{$\begin{array}{l}\text { Behaviour relating to self- } \\
\text { harm/suicide }\end{array}$} & Facilitating self harm & $\begin{array}{l}\text { Hid parts of body from nursing staff (to conceal self harm) } \\
\text { Refused adequate diet } \\
\text { Tried to obtain objects with which to self harm }\end{array}$ \\
\hline & & Self harming behaviour & $\begin{array}{l}\text { Attempted self injurious behaviour } \\
\text { Hit body parts against the wall (punching, head butting) }\end{array}$ \\
\hline & & Facilitating suicide & $\begin{array}{l}\text { Giving away/selling personal possessions } \\
\text { Planned/expressed intention or means of suicide }\end{array}$ \\
\hline \multirow{4}{*}{ VIOLENCE/THREATS } & Violent behaviour & Violent behaviour & Been physically violent (hitting, pushing and swinging at others) \\
\hline & \multirow{3}{*}{ Threatening/hostile behaviour } & Threatening behaviour & Shown threatening/hostile behaviour \\
\hline & & Thoughts of violence & Communicated plan or intention to harm others \\
\hline & & Property damage & Damaged property \\
\hline
\end{tabular}




\begin{tabular}{|c|c|c|c|}
\hline \multirow{4}{*}{ NEGATIVE INFLUENCE } & \multirow{2}{*}{ Negative influence on peers } & Bullying & Bullying behaviour towards others \\
\hline & & Grooming & $\begin{array}{l}\text { Asking other service users to attack staff } \\
\text { Displaying grooming behaviour towards others }\end{array}$ \\
\hline & \multirow[t]{2}{*}{ Subversion/conspiracy } & Subversive & $\begin{array}{l}\text { Appearing under the influence of substances } \\
\text { Attempting to abscond } \\
\text { Drinking excessive volumes of liquid } \\
\text { Evidence of subversion/security risks }\end{array}$ \\
\hline & & Active resistance & $\begin{array}{l}\text { Indications that they had no plan to become well/ move on } \\
\text { Requesting removal/review of constant observations }\end{array}$ \\
\hline \multirow{2}{*}{ DISENGAGEMENT } & \multirow{2}{*}{ Disengagement } & Despondent & $\begin{array}{l}\text { Communicated low self esteem } \\
\text { Expressed hopelessness or despair }\end{array}$ \\
\hline & & Disengaged & $\begin{array}{l}\text { Avoidance of people/activities they would normally welcome } \\
\text { Disengaged from others and from activities }\end{array}$ \\
\hline \multirow{6}{*}{ POSITIVE BEHAVIOUR } & \multirow{2}{*}{ Stable presentation } & Active coping & Utilised coping strategies \\
\hline & & Positive presentation & $\begin{array}{l}\text { Presented as more positive } \\
\text { Was calm }\end{array}$ \\
\hline & \multirow[b]{2}{*}{ Positive engagement } & Social engagement & $\begin{array}{l}\text { Engaged and held appropriate, open dialog } \\
\text { Engaged appropriately with peers or staff } \\
\text { Engaged in activity }\end{array}$ \\
\hline & & Therapeutic engagement & $\begin{array}{l}\text { Engaged in therapeutic relationship with staff } \\
\text { Communicated therapeutically with staff regarding their situation } \\
\text { Rationalised own behaviour without minimisation } \\
\text { Reflection/insight on reason for being on observations }\end{array}$ \\
\hline & \multirow[t]{2}{*}{ Accepting support } & Compliant with care & $\begin{array}{l}\text { Complied with medication } \\
\text { Conformed to treatment } \\
\text { Requested or collaborated with health promotional programmes }\end{array}$ \\
\hline & & Accepting support & $\begin{array}{l}\text { Accepted support } \\
\text { Communication of increased stressors }\end{array}$ \\
\hline $\begin{array}{l}\text { INDIVIDUAL } \\
\text { INDICATORS }\end{array}$ & Individual indicators & Individual indicators & Displayed relapse indicators \\
\hline
\end{tabular}

